\title{
TESTING DJI PHANTOM 4 PRO FOR URBAN GEOREFERENCING
}

\author{
Mariana de Sá Rodrigues da Silva*, Ricardo Augusto Eger, Yuzi Anai Zanardo Rosenfeldt, Carlos Loch \\ University of Santa Catarina, João Pio Duarte Silva, 57-149 - Córrego Grande, Florianópolis - SC, 88037-001, Brazil, \\ maridesa.arquitetura@gmail.com
}

\section{Commission ICWG I/II}

KEY WORDS: Small UAVS, Image Processing, GCP, Urban Property Stock Georeferencing, Urban Parcel Georeferencing, Geometric Accuracy

\begin{abstract}
:
The urban environment is dynamic and is constantly changing. In Brazil, it has been recently published a decree for urban land regulation for the cadastre - Decree No 9.310 of 201815 of March which fixes 8,0 centimeters as the maximum spherical positional error for vertex of an urban property stock being georeferenced by Global Navigation Satellite System - GNSS equipment or aerial orthophotograph. Nowadays it has been noticed a growing use of Unmanned Aircraft Vehicle System - UAVS for remote sensing. This work aims to test if the accuracy of orthophoto-mosaic from a small UAVS mapping data of an urban area for a parcel scale georeferencing is answering the new decree of urban land regulation for the cadastre. It is intended to check the number of Ground Control Points (GCPs) to reach the best quality in terms of geometric resolution according to the necessity of positional quality for the urban parcel georeferenced for the cadastre. As a final consideration, the results implied that mapping a small surveying area with small UAVS is worth, being a potential tool for georeferencing city blocks, and using 20 pairs of GCPs is enough to reach the quality of positional geometry adequate to the Brazilian legislation.
\end{abstract}

\section{INTRODUCTION}

The urban environment is constantly in change. In Brazil, the process of urban land occupation often takes place by invasion from less favourable socio-economic group who lack housing policies and programs or from irregular enterprises and activities or even regularized by legal changes on behalf of particular interest.

The Brazilian territorial policy about land regulation is based on the Brazilian Civil Code (Law No 10.406 of 2002, 10 January) (Brasil, 2002) and on the City Statute (Law No 10.257 of 2001, 10 July) (Brasil, 2001). It has recently been published a decree for urban land regulation for the cadastre (Decree No 9.310 of 201815 march) (Brasil, 2018) which fixes eight centimeters as the maximum spherical positional error for vertex of an urban property stock being georeferenced by Global Navigation Satellite System - GNSS equipment or aerial orthophotograph.

For an effective management and monitoring of the urban land use and occupation it is required quality of information, therefore it is necessary advanced techniques. The remote sense represents an important tool to obtain information of the urban environment. The development of information processing has been occurring in terms of greater availability and less difficulties of access with new systems of sensors, new procedures of images processing and the development of hardware and software. Nowadays it has been seen a growing use of Unmanned Aircraft Vehicle System - UAVS for remote sensing which represents low-cost alternative to the classical manned aerial photogrammetry and the possibility of high temporal resolution (Eisenbeiss, 2009).

The greatest advantages in using UAVS is that it is possible to face risky situations without endangering a human life and to reach inaccessible areas. Another advantage is the possibility of data acquisition in cloudy and drizzly weather conditions when the distance to the object permits flying below the clouds.
Furthermore, it is able near- or real-time data acquisition for monitoring (Eisenbeiss, 2009). The greatest limitation of UAVS, especially low-cost ones, is the weight and dimension of its payload which is limited to small and medium format cameras, therefore, it requires a higher number of images for the same area covered by a larger format camera, also, they are limited to the reached altitude. Furthermore, they are less stable than usual photogrammetric techniques and because of the payload limitation they are able to carry only small navigation units. These factors imply a reduced image quality and a less accurate orientation of the sensors (Eisenbeiss, 2009).

According to the necessity of positional quality for the urban parcel georeferenced for the cadastre, and consequently, in the management and assessment of urban land use and occupation, the promising use of UAVS for mapping the environment is believed to be of important use due to being a method of low costs and easy manipulation, but the quality of this method still must be verified. Therefore, this work aims to test the accuracy of orthophoto-mosaic from a small UAVS mapping data of an urban area for a parcel scale georeferencing in order to answer to the new decree for urban land regulation for the cadastre. It is intended to check the number of Ground Control Points - GCPs that should be reasonable in order to reach the best quality in terms of geometric resolution.

The presented work treats an exploratory descriptive study with a quantitative approach and it employs investigative methods with UAV remote sensing data. It was used the Phantom 4 Pro of $1,388 \mathrm{Kg}$ weighted with a one-inch CMOS sensor and $20 \mathrm{MP}$ for mapping data of an urban area at the city of Joinville, SC, Brazil. The image process of orthorectification was made with a commercial software, the PhotoScan and it was georeferenced with GCPs. 


\section{GEOREFERENCING UAVS MAPPING DATA}

There are two options on georeferencing UAV mapping data: (i) indirect georeferencing, using ground control points - GCPs, which is time consuming and not always found in accessible areas, not real-time capable and requires a high overlapping; (ii) directed georeferencing, which requires an on-board multi sensor system, not being easily adapted to small and lightweight UAVS (Eling et al, 2015). The scale of a processed image is related with the size of the pixel, called ground sample distance - GSD.

A ground control point - GCP is an object point which can be identified in the image and from which the accurate threedimensional object (terrain) co-ordinates $(\mathrm{x}, \mathrm{y}, \mathrm{z})$ are known. The GCPs can be signalized and an existing feature can be identified at the image. The contemporary significant way of getting the co-ordinates from a GCP is using a Global Position System GPS equipment (Linder, 2006). For georeferencing in standard digital photogrammetry, in case of a single model formed by two images, it is necessary at least three welldistributed GCPs, therefore it is recommended to look for at least five points and at least three of them must form a triangle. In case of a block formed of " $n$ " strips a standard rule is to have one GCP in every third model at least near the borders of the block, and if necessary additional height points inside the block (Linder, 2006). It is better to have more rather than a few GCPs and they should be dispersed throughout the image with good coverage near the borders and it is recommended 16 GCPs as a reasonable number if each of them can be located with an accuracy of one-third of a pixel (Campbell \& Wynne, 2011). To check the position accuracy of a processed orthoimage the standard measure is the root mean square error-RMSE, which refers to the deviation of the difference between surveyed positions of GCPs and their positions at the image. The American Geographic Data Committee mention a minimum of 20 points to be checked (Federal Geographic Data Committee, 1998).

Early examples of UAVS products using GCPs can be seen in Eisenbeiss (2009): (i) The archeological map by images taken from a medium format camera mounted on a BCV D4 balloon in 1983 by Vozikis, when six photographs were taken from a height of about 25 meters and these formed three stereo models with irregular overlap between the photographs. The images were oriented in analytical plotting system and with five GCPs, which resulted in a Root Mean Square Error - RMSE of 1,5 centimeters planimetric and 4,0 centimeters in height; (ii) the generation of a 3D-model of a historical mill, in which was taken 82 pictures from the ground and 32 images from a small format amateur camera mounted on a UAVS helicopter, where it was used the excessive number of 120 GCPs for the model exterior orientation which resulted in an average RMSE of 2,0 $\mathrm{cm}$ in planimetry and height. Eisenbeiss (2009) presents his results of the photogrammetric processing for the east court of Copán archeologic heritage by UAVS helicopter flight. The orientation of 22 images using 5 GCPs resulted in an accuracy value of 2,0 centimeters planimetry and 1,0 centimeter height.

Other works more related to this research have shown the process of orthorectification: Duarte \& Gonçalves (2014) used the mini UAVS fixed wings Swinglet CAM with only 500 grams of weight carrying a small format $12 \mathrm{MP}$ camera to cover an area of about $0,28 \mathrm{~km}^{2}$ and 11 GCPs which resulted in an RMES of 19 centimeters; Souza (2015) reached a RMSE of 12 $\mathrm{cm}$ for a $1,0 \mathrm{Km}^{2}$ area with $34 \mathrm{GCPs}$ using the same UAVS.

\section{RESEARCH METHODS}

The urban area mapped at the city of Joinville is a neighborhood called Comasa with an area of $2,8 \mathrm{~km}^{2}$ approximately. The estimated population in 2015 was 21.379 inhabitants, therefore, the population density of 7.860 inhabitants per square kilometer (IPPUJ, 2015). It is in constant process of densification and verticalization. The surface of the area is plane; thus, the relief will not influence in the tests.

The preliminary intention was to map the whole area of the neighborhood. Therefore, it was firstly surveyed the whole area and tested the image processing. As the results found did not reach a satisfactory positional accuracy, another flight was performed covering only an area equivalent to $1 \mathrm{~km}^{2}$ on its whole.

\subsection{Field Surveying}

As already mentioned in the introduction, aerial surveying was performed using the Phantom 4 Pro UAV model that weights $1,388 \mathrm{~kg}$ with a one-inch $20 \mathrm{MP}$ CMOS sensor.

The flight plans were done by the DroneDeploy free software, it was established 120 meters of flight height because it makes the procedure less bureaucratic once the Brazilian rules of the National Agency of Civil Aviation - ANAC do not demand flight authorization for small classes UASV until this height of flight. Another reason was that at this height, with a small format camera it is possible to get a good pixel size. The overlay of the taken pictures were $80 \%$ on front line and $60 \%$ on side line.

The GCPs co-ordinates were surveyed by GNSS equipment. The RTK (Real Time Kinematic) method was used in the mapping tests of the $2.8 \mathrm{~km}^{2}$ area. The number of 46 pairs of GCPs were collected between, materialized with $\mathrm{X}$ target on ground made by white painting as well as identifiable features in the image. In the tests related to the $1 \mathrm{~km}^{2}$ area it was surveyed 30 pairs GCPs, those were carried out by the NTRIP (Networked Transport of the Radio Technical Commission for Maritime Services via Internet Protocol) method taking reference from the Araquari Station, one of the stations of the Brazilian GNSS Systems Continuous Monitoring Network, which was not available when the surveying of the $2,8 \mathrm{~km}^{2}$ area was done. Figure 1 shows the Phantom 4-Pro used and Figure 2, a GCP being surveyed.

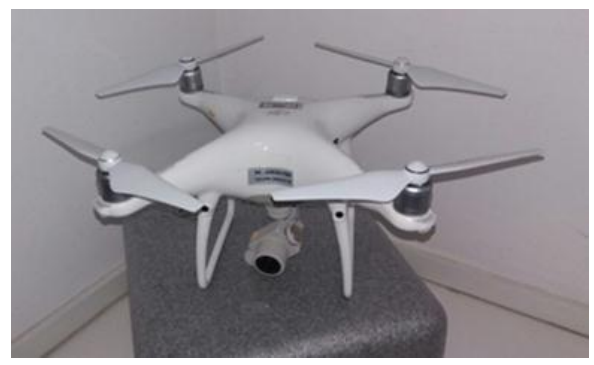

Figure 1. Phantom 4-Pro used. 


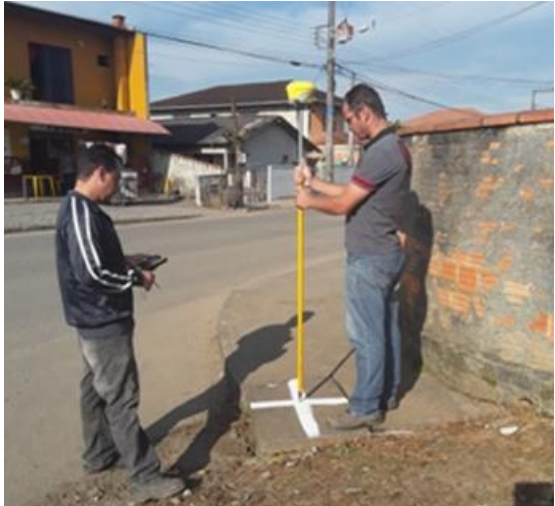

Figure 2. a GCP being surveyed.

\subsection{Image processing}

The images were processed by the PhotoScan commercial software. The first process was the alignment of the photos, generating a sparse cloud of points and, after that, a dense cloud point was created for building the digital elevation model DEM hence the orthophoto mosaic was generated. In order to get the image orientation, the use of GCPs was done at this last step of the image processing.

Four tests were performed at the orthophoto-mosaics processing: (i) in the tests referring to the $2.8 \mathrm{~km}^{2}$ area surveyed, first it was used 47 CGPs referring to each one of the surveyed pairs; (ii) after, the image processing for the $2,8 \mathrm{~km}^{2}$ area was done by decreasing the number of GCPs to 20 considering a good distribution and well covering of the edges; (iii) as to the $1 \mathrm{~km}^{2}$ area, at first it was used 30 CGPs referring to each one of the surveyed pairs and then; (iv) the image processing for the $1 \mathrm{~km}^{2}$ area was done like the $2,8 \mathrm{~km}^{2}$ area by decreasing the number of GCPs to 20 , as well, considering a good distribution and well covering of the edges. The second tests for each area were executed by reducing the number of GCP with the purpose to verify the possibility of optimizing fieldwork, checking the difference between the results with more or less number of GCPs.

\subsection{Checking the position accuracy}

In order to check the position accuracy, it was estimated the difference between the point of the image and its real coordinates using Geographic Information System - GIS (ArcMap 10.5) and then calculated the RMSE for each aerial orthophoto mosaic.

\section{RESULTS AND DISCUSSION}

At this section it is presented the results of aerial surveys and the positional accuracy of the orthophoto-mosaics processed for the areas of $2,8 \mathrm{~km}^{2}$ and $1 \mathrm{~km}^{2}$ with different numbers of GCPs.

\subsection{The $2,8 \mathrm{~km}^{2}$ surveyed area}

The surveyed area of $2,8 \mathrm{~km}^{2}$ had the flight lines established on west-lest starting from north taking into account the wind condition for the optimization of the flight. The software planed five flights to cover the whole area resulting in one and a quarter hour for the survey which was not possible, due to the aerial platform that constantly lost contact with the terrestrial equipment control and stopped taking pictures. That have resulted in an increasing number of flights and problems with batteries discharges. Thus, because of the lack of appropriated sunlight conditions at evening, it was necessary to do some of the flights another day. The aerial survey of the area resulted in 2.014 pictures to be processed into an aerial orthophoto-mosaic with 3,0 centimeters of GSD, limited by the software processing because of the great number of photos.

The RMSE resulted from the orthophoto-mosaic processing with 47 and 20 GCPs was 14,45 and 14,23 centimeters respectively, which does not reach the positional accuracy for urban property stock georeferencing asked in the Brazilian civil code and specified by the new decree of urban land regulation for the property register. Figure 3. Shows the orthophotos georeferenced with 47 and 20 GCPs respectively and the checking points used for the measurement of the RMSE
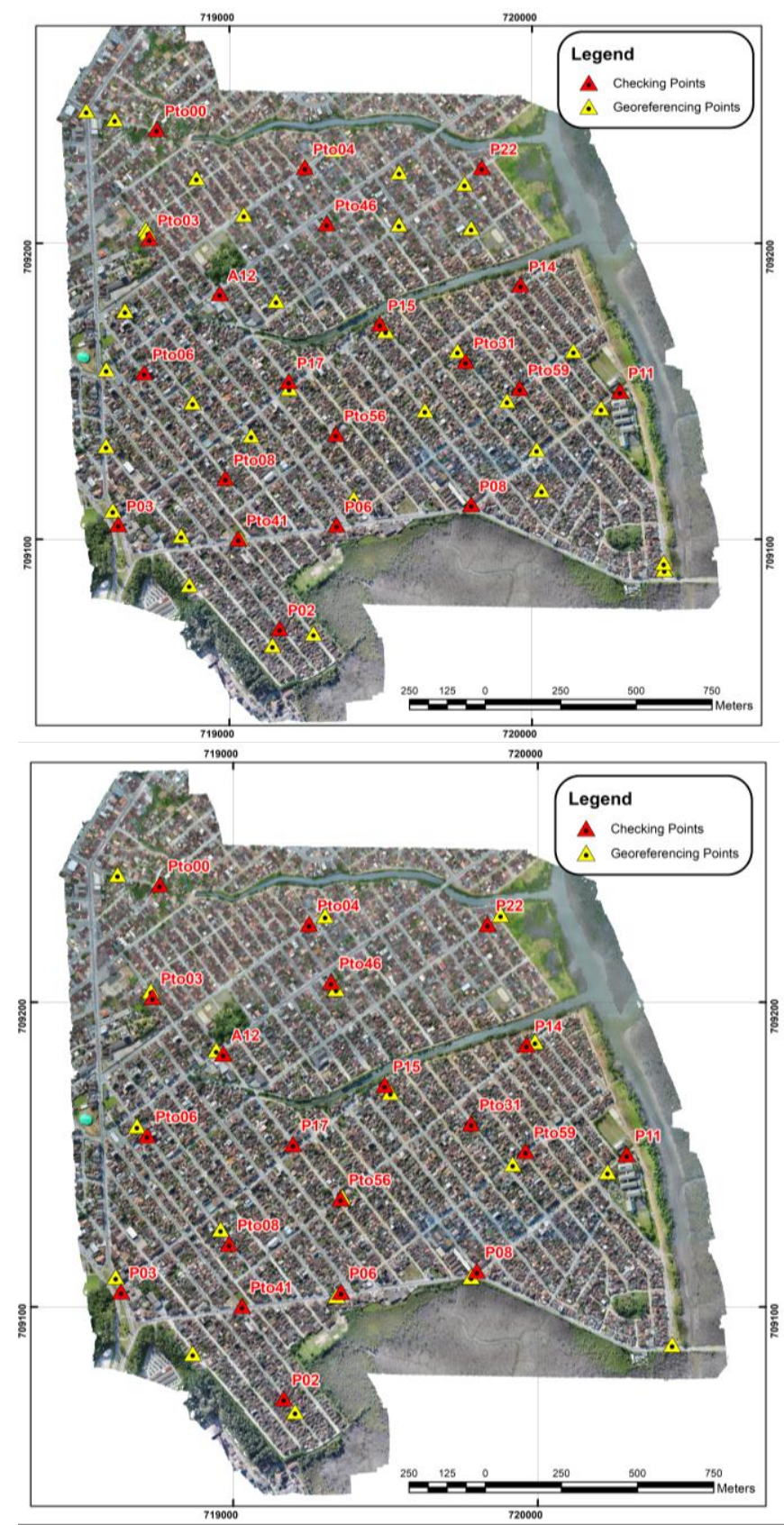

Figure 3. Orthophoto of the $2,8 \mathrm{~km}^{2}$ area surveyed georeferenced with 47 and 20 GCPs and checking points used for the measurement of the RMSE 


\subsection{The $1,0 \mathrm{~km}^{2}$ surveyed area}

For the $1,0 \mathrm{~km}^{2}$ area surveyed the Dronedeploy software planed three flights to cover the area. The flight was done from around $10 \mathrm{~h} 30 \mathrm{~min}$ to about $12 \mathrm{~h} 00 \mathrm{~min}$, most of the time with clear sun light and an appropriate wind for the flight, which was varying from $12 \mathrm{~m} / \mathrm{s}$ to $9 \mathrm{~m} / \mathrm{s}$. The aerial survey resulted in 614 pictures to be processed into an aerial orthophoto-mosaic with 1,0 centimeter of GSD.

The RMSE resulted of the orthophoto-mosaic processing with 30 and 20 GCPs was 2,5 and 2,3 centimeters respectively, which represent a great result once the accuracy for urban property stock georeferencing proposed for the Brazilian legislation is $8,0 \mathrm{~cm}$. Figure 4. Shows the orthophotos georeferenced with 30 and 20 GCPs respectively and the checking points used for the measurement of the RMSE.
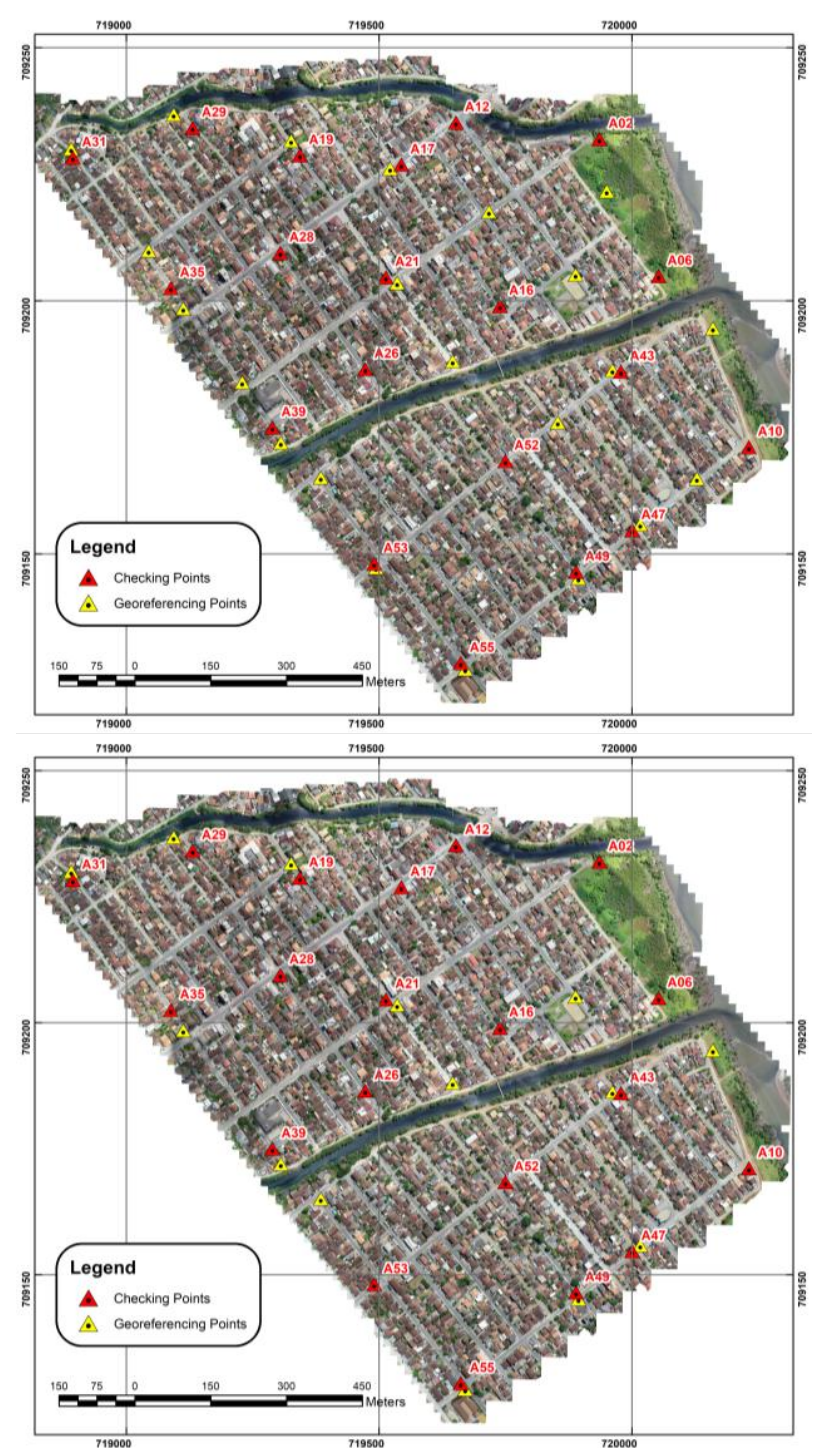

Figure 4. Orthophoto of the $1,0 \mathrm{~km}^{2}$ area surveyed georeferenced with 30 and 20 GCPs and checking points used for the measurement of the RMSE

\subsection{Results discussion}

As it is seen in table 1 , the orthophotos processing with 20 GCPs or more did not present any representative difference between in the RMSEs reached in each area. It shows that the decrease of the number of GCPs for processing the orthophoto almost had no influence in georeferencing the product, therefore it is possible to have less work field and have practically the same result.

\begin{tabular}{|c|c|c|}
\hline $\begin{array}{c}\text { Area } \\
\text { surveyed } \\
\left(\mathrm{km}^{2}\right)\end{array}$ & $\begin{array}{c}\text { Number of GCP for } \\
\text { processing the } \\
\text { orthophoto mosaic }\end{array}$ & $\begin{array}{c}\text { RMSE 20 } \\
\text { Checking Points } \\
(\mathrm{cm})\end{array}$ \\
\hline 2,8 & 47 & 14,45 \\
\hline 2,8 & 20 & 14,23 \\
\hline 1,0 & 30 & 2,6 \\
\hline 1,0 & 20 & 2,5 \\
\hline
\end{tabular}

Table 1. Results

However, for the area of $2,8 \mathrm{~km}^{2}$ the orthophoto processed did not reached the accuracy needed for georeferencing an urban property stock. Nevertheless, the experience on the aerial surveyed was quite laborious because of the constantly loss of contact between the terrestrial base equipment and the aerial platform, which evidences the need of a well-planned aerial survey, predicting site changes of the terrestrial base equipment control in order to not loose contact with the aerial platform.

Yet the results of the $1,0 \mathrm{~km}^{2}$ area surveyed were very satisfactory. The field work showed no difficulty to be done in one day of work. Also, the orthophoto processed with $1,0 \mathrm{~cm}$ of GSD presented higher positional quality, the RMSEs resulted for processing with $30 \mathrm{GCPs}$ and $20 \mathrm{GCPs}$ were around the same and fits very well on the accuracy for urban property stock georeferencing proposed by the Brazilian regulation. It is worth to remember about the ideal weather conditions at the flight day which probably also has influenced this great result.

\section{CONCLUSION}

This work approached the urban mapping of a plane area and is limited on checking only the planimetry accuracy of the processed orthophoto mosaics.

The results implied that for mapping a small surveying area by small UAVS, like $1,0 \mathrm{~km}^{2}$, it is worth, and it is a potential tool for georeferencing city blocks, once it has reached 2,4 centimeters of positional accuracy while the Brazilian legislation admits the maximum of 8,0 centimeters of positional error. Additionally, the use of $20 \mathrm{GCPs}$ in the orthophoto processing demonstrated being satisfactory.

\section{ACKNOWLEDGEMENTS}

We would like to thank the Coordination of Higher Education of the Brazilian Government - CAPES who provided the funding for the fields surveying of this project, equipment for the image processing, and funded the conference attendance, including the scholarship of one of the authors.

We also would like to thank the National Council for Scientific and Technological Development for the scholarship of the authors.

\section{REFERENCES}

Brasil, G. F. (2001). Lei no 10.257, de 10 de julho de 2001. Estatuto da Cidade. Diário Oficial da União, Seção 1, eletrônico, 11/7/2001. Available <http://www2.camara.leg.br/legin/fed/lei/2001/lei-10257-10- 
julho-2001-327901-norma-pl.html>. Access in: 2018, march 30 .

Brasil, G. F. (2002). Lei 10.406 de 10 de janeiro de 2002. Código Civil. Diário Oficial da União, Seção 1, 11/1/2002. Available <http://www.planalto.gov.br/ccivil_03/leis/2002/L10406compil ada.htm> Access in: 2018, march 30.

Brasil, G. F. (2018). Decreto n 9.310, de 15 de março de 2018. Regularização Fundiária Urbana. Diário Oficial da União. Brasília, DF, 16/03/2018. Available in: <http://www2.camara.leg.br/legin/fed/decret/2018/decreto9310-15-marco-2018-786319-publicacaooriginal-155038pe.html>. Access in: 2018, march 30.

Campbell, J. B., \& Wynne, R. H. (2011). Introduction to remote sensing. Guilford Press.

Duarte, D., \& Gonçalves, G. (2014). Produção automática de ortofotos em áreas urbanas utilizando veículos aéreos não tripulados e software de código aberto. Atas das Jornadas Lusófonas de Ciências e Tecnologias da Informação Geográfica, Coimbra, 11, 705-722.

Eisenbeiss, H. (2009). UAV Photogrametry. PhD Thesis University of Technology Dresden.

Eling, C., Wieland, M., Hess, C., Klingbeil, L. and Kuhlmann, H. (2015). Development and Evaluation of a UAV based Mapping System for Remote Sensing and Surveying Applications. ISPRS - International Archives of the Photogrammetry, Remote Sensing and Spatial Information Sciences V. XL-1/W4, 233-239.

Federal Geographic Data Committee. (1998). Geospatial Positioning Accuracy Standards, part 3: National standard for spatial data accuracy. Subcommittee for Base Cartographic Data, 25p.

IPPUJ - Fundação Instituto de Pesquisa e Planejamento para o Desenvolvimento Sustentável de Joinville (1015). Joinville Bairro a Bairro 2015. Joinville: Prefeitura Municipal de Joinville. 106p.

Linder, W. (2006) Digital Photogrammetry: Theory and Applications. Berlin: Springer-Verlag, 189 p.

Souza, G. D. (2015). Análise da viabilidade do uso de VANT para mapeamentos topográfico e de cobertura e uso da terra. 